\title{
AUSTRALIAN HOTEL ORGANISATIONS AND THEIR PRE AND MID COVID-19 ORGANISATIONAL RESILIENCE
}

\author{
Kathleen Pittello ${ }^{1}$, Kartik Malik ${ }^{2}$, Abhishek Pandya ${ }^{3}$, Sai Sireesha Gunturi ${ }^{4} \&$ Thu-Huong Nguyen ${ }^{5}$ \\ 1,2,3,4,5 Victoria University School of Business Melbourne
}

(kpittello@gmail.com, kartikmalik454@gmail.com, abhishek.pandya192@gmail.com, sireeshavarma.03@

gmail.com, thu-huong.nguyen@vu.edu.au)

\begin{abstract}
This study focuses on the Australian hotel organisation and their organisational resilience (O.R.) during the Covid-19 pandemic. Its objectives are to leverage the "Hotel Resilience model" developed by MeliánAlzola et al. (2020) and the Benchmark Resilience Tool to gain indications of the level of O.R of the Australian hotel sector, to determine the relationship between the hotel O.R. indicators and the financial outcomes and to document O.R. related tactics and strategies implemented in the Australian hotel industry during the Global pandemic. By adopting a qualitative research approach using experts' interviews with 10 hotels general or operations managers, the study found that there was no formal awareness of or adoption of formal O.R. frameworks within the participating hotels nor was there any indication of an appetite for the implementation of any O.R. frameworks, also as a result of lack of data, the study was unable to determine a link between O.R. indicators and financial outcomes.
\end{abstract}

KEYWORDS: Organisational Resilience Practice, Global Pandemic, Australian Hotel Sector, Covid-19

\section{PURPOSE AND BACKGROUND}

The COVID-19 pandemic has affected business performances across the globe and across many industries, amongst which the hospitality industry is significantly affected. Hotels within Australia must ensure that they have Organisational Resilience (O.R.). O.R. practices are key to both manage a crisis effectively and ensure that a business is in place for the long term. This research is therefore to determine the effects of the global pandemic on hotel business performance.

\section{METHODOLOGY}

This research adopted a qualitative research approach using experts' interviews with 10 hotels general or operations managers. It provides insights into O.R. practices within the Australian hotel industry, effected of the global pandemic on hotel management, areas for targeted improvement within the O.R. to strengthen the industry, while the overall O.R. awareness and capabilities mature. By using constant comparison analysis approach, the data was analysed to compare pre and post COVID-19 situations, and recurring themes of actions taken or plans to address O.R.

\section{FINDINGS}

The research on first objective (what was the level of Organisational Resilience of the Australian hotel industry?) found that there was no formal awareness of or adoption of formation O.R. frameworks within the participating hotels. The findings on the second objective (determine whether hotels with high O.R. indicators fared well during the COVID-19 crisis (as measured by profit increase or decreases between 
March 2019 and March 2021)) and was difficult to determine with only half of the hotel managers providing accurate details of profitability. The consequence of sample size meant that it was unable to be determined whether there is a link between strength in O.R. indicator activities and the financial performance.

The final objective targeted was to determine both if the Australian hotel industry has put in place O.R. measures, and if so what strategies or tactics they have planned/implemented. There was no indication of any appetite for the implementation of any Organisational Resilience frameworks. The focus of leaders within the industry trended towards risk mitigation.

Despite these outcomes, there was a strong level of acceptance of and the desire for the risk management practices of crisis management or business continuity planning, elements of O.R. (MeliánAlzola et al., 2020), which may be a good foundation for O.R. framework implementation.

\section{CONCLUSION}

Comparison of the hotel O.R. approaches, before Covid-19 and at this time have indicated crisis management and adaptive behaviours (in response to customer requirements or issue resolution) appears to be embedded into the Australian industry, yet the concepts of overall O.R. has not yet reached the Australian hotel industry and may be ripe for development.

It is noted that the confidence in risk (crisis/incident) management practices/skills demonstrated by many leaders interviewed may lead to some resistance to acceptance of the possibility that there is room for improvement or a need to consider O.R.

\section{CONTRIBUTION/PRACTICAL IMPLICATIONS}

It is recommended that industry leaders across hotels (CEO's, owners and hotel managers) consider the strategic perspective of Organisational Resilience rather than pure risk management (disaster recovery, crisis or incident management etc.)

The revealed areas for targeted improvement within the O.R. indicators are Decision Making, Internal Resources and Stress Testing of Plans: an uplift in these internal capabilities will strengthen the industry, while the overall O.R. awareness and capabilities mature.

\section{REFERENCES}

Brown, C., Seville, E., \& Vargo, J. (2017). Measuring the organizational resilience of critical infrastructure providers: A New Zealand case study. International Journal of Critical Infrastructure Protection, 18, 37-49. https://doi.org/10.1016/j.ijcip.2017.05.002

Campbell, D. J., Edgar, D., \& Stonehouse, G. (2011). Business strategy: An introduction (3rd ed.). Palgrave Macmillan.

Melián-Alzola, L., Fernández-Monroy, M., \& Hidalgo-Peñate, M. (2020). Hotels in contexts of uncertainty: Measuring organisational resilience. Tourism Management Perspectives, 36, 100747. https://doi. org/10.1016/j.tmp.2020.100747 